\title{
Weld Metal Microstructures on Dissimilar Steels Laser Beam Welded Joints
} S.Missori

Dept. of Mech.Engineering-University of Rome-Tor Vergata-Via Politecnico-00133-Roma-Italy

Austenitic stainless steels are extensively used for good resistance to corrosion. When these steels are to be welded to ferritic steels (e.g. dissimilar joints, clad steel joints), usually a stainless steel filler metal is provided and weld metal may be hot-crack sensitive. To minimize this tendency, the composition of weld metal should preferably consist of an austenitic structure with small amount of $\delta$ ferrite [1]. Generally, a variety of structures can be formed during solidification of weld metal, depending on compositions of filler and base metals. Useful indications on weld structure can be deduced from a constitution diagram. Well known is the Schaeffler diagram, which defines the existence field of phases depending on composition expressed as $\mathrm{Cr}_{\mathrm{eq}}, \mathrm{Ni}_{\mathrm{eq}} \%$ [2]. Over the years alternative constitution diagrams have been proposed in order to better characterize phases within specific ranges of composition, e.g. in austeno-ferritic field [3] or along martensitic boundary [4]. However, the Schaeffler diagram continues to be used, because it includes larger boundary limits (e.g. for predicting martensite appearance).

In our work, aiming to assess Laser Beam Welding procedures for joining 304 stainless steel to ferritic steels, extensive welding trials on dissimilar steels and clad steel were experimented. Several filler metals and welding parameters were used, giving rise to numerous weld metal samples. The contents of elements were evaluated either by X-Ray EDS microanalysis ( $\mathrm{Cr}$,Ni, see Fig.1), or calculated, basing on contents in filler and parent metals. Some experiments gave rise to satisfactory results in terms of weld metal composition and soundness (i.e. free from martensite, final structure of austenite with little $\delta$ ferrite); these "good" results are reported in previous papers $[5,6]$. In many cases however, the structures did not achieve the desired composition, as the content of $\mathrm{Cr}_{\text {eq }}$ ranged from 2 to $25 \%$, while the content of $\mathrm{Ni}_{\text {eq }}$ was within 4 and $25 \%$. The observed structures, other than austenitic-ferritic, were found to be either fully-martensitic or austenitic-martensitic (e.g. see Fig.2) or fully austenitic respectively. All calculated couples $\mathrm{Cr}_{\text {eq- }}{ }^{-}$ $\mathrm{Ni}_{\text {eq }}$, according to Schaeffler criterion, were reported on the diagram (Fig.3). The structures were observed by optical/SEM microscopy and submitted to hardness tests. Hardness of fully-austenitic and austenitic-ferritic structures are within $150 \ldots 250 \mathrm{HV}$, austenitic-martensitic structure within $240 \ldots 430 \mathrm{HV}$ and fully-martensitic structure within $405 \ldots 480 \mathrm{HV}$. Hardness values are reported on Fig. 3 to characterize the various structures. It is interesting to compare the observed structures with the predictions of Schaeffler diagram along the boundary between fully-austenitic and austeniticmartensitic fields.In Fig.3, if we assume that a weld metal with $\mathrm{HV}<210$ is virtually free of martensite, the boundary line of the martensite-free weld metal should be moved downward to comply with experimental data. Doing so, these data would better fit with the recently proposed new martensite boundary on the WRC-1992 diagram [4]. If we transpose this boundary into the Schaeffler diagram, the prediction of weld metal structures appears closer to the experimental evaluation. It is to be noticed that generally LBW process may submit weld metal to higher cooling rates than conventional welding processes, with possible deviation from predicted structures [8]. However, in our trials the estimated rates had the same order of magnitude as typically in multipass arc welding [5].

\section{References}

[1]Brooks J.A.et al.,1984. Study of the Beneficial Effects of Delta Ferrite.-Weld.J. 63 (3),71s to 83s. [2]Schaeffler, A.L.1949.Constitution Diagram for Stainless Steel Welds. Metal Progress 56(11):680-680B.

[3]Kotecki D.J.,1992.WRC-1992 Constitution Diagram for Stainless Steel Welds-Weld.J.71 (5):171s to 178s. [4]Kotecki D.J.,1999. A Martensite Boundary on the WRC-1992 Diagram -Weld.J.71 (5):180s to 178s.

[5]Missori S.et al.,1998,Procedure.. for ..LBW of Dissimilar Metals, Weld. J.-77(6): 232s- to 238s.

[6]Missori S.et al.,2004,Single-Pass LBW of Clad Steel, Weld.J.-65 (2)65s-71s.

[7]David S.A,1987. Effect of rapid Solidification on Stainless Steel Welds etc -Weld.J 66 (10):289s to 302s. [8]KujanpaaV.P,1986.Solidification Cracking in Austenitic Stainless Steel Welds-Weld.J.65(8):203s to 212s. 


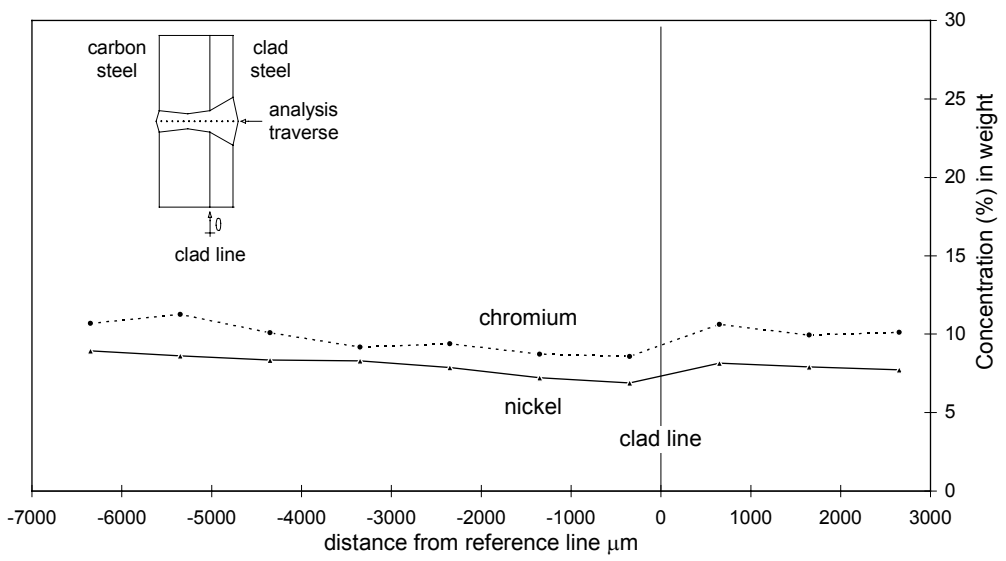

Fig.1-Estimation of $\mathrm{Cr}$ and $\mathrm{Ni}$ content along weld metal by X-Rays EDS microanalysis in a clad steel LB welded joint.

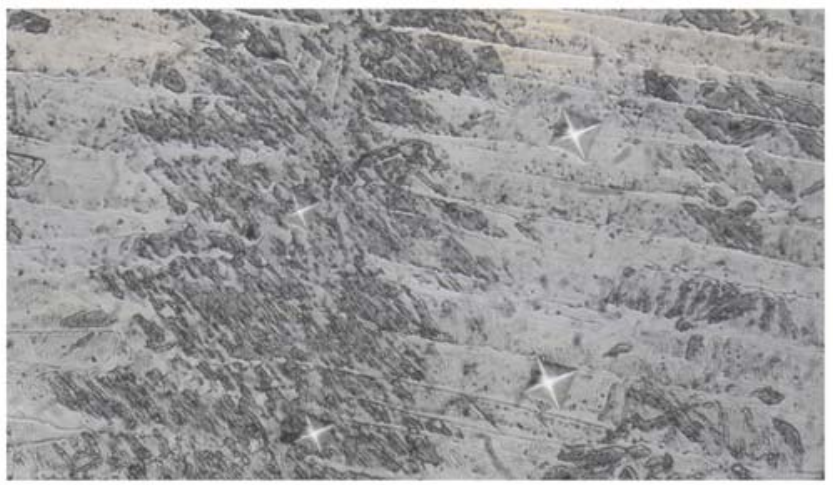

Fig.2- Micrograph of a austenitic-martensitic weld metal structure (500X) Microhardness martensite(dark) $430 . .460 \mathrm{HV}$, austenite (light) $230 . .240 \mathrm{HV}$

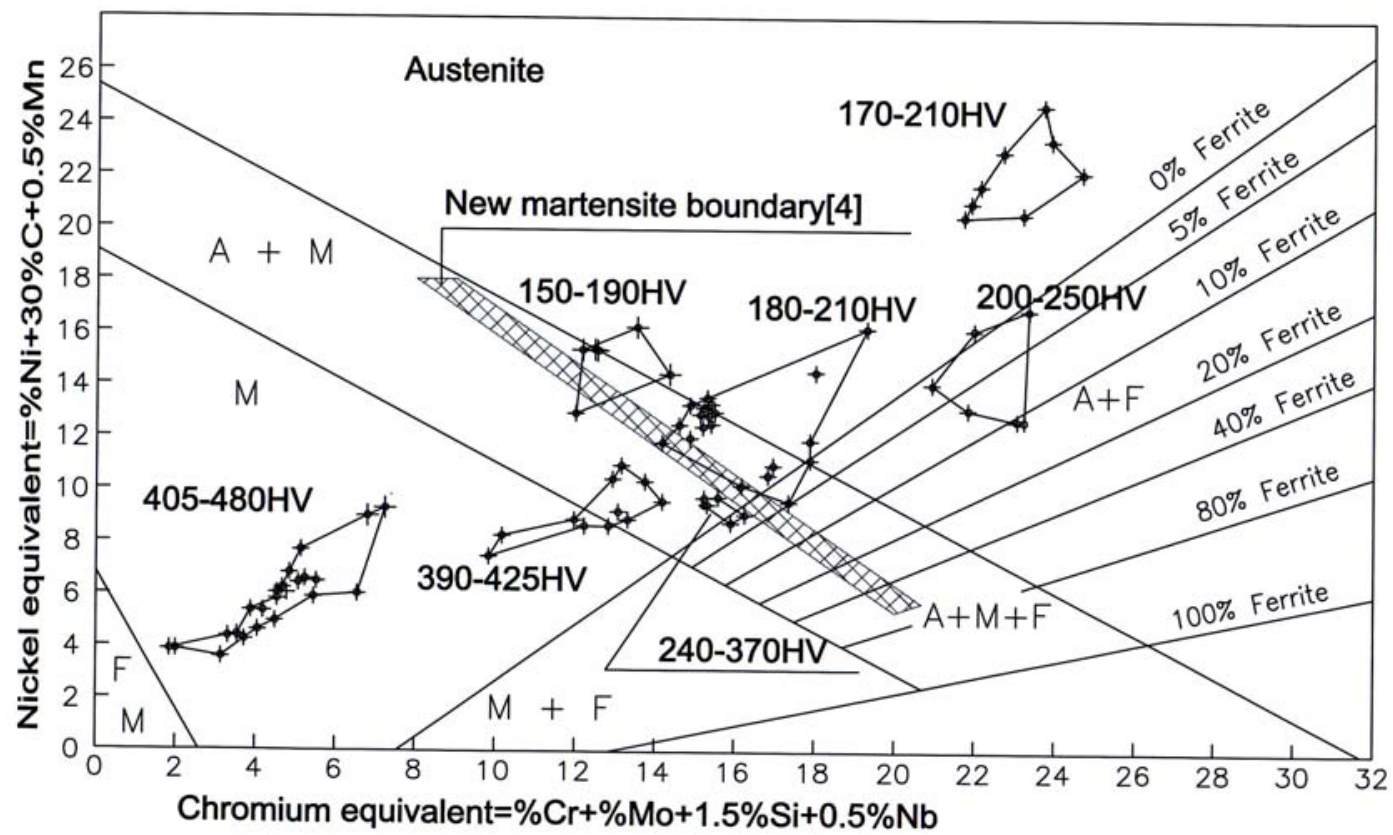

Fig. 3- Structures indicated by Schaeffler diagram with HV microhardness ranges, measured along weld cross section- Results are not easily predictable inside the boundary dashed area. 